Terbit online pada laman web jurnal : http://teknosi.fti.unand.ac.id/

\title{
Analisa Link Balancing dan Failover 2 Provider Menggunakan Border Gateway Protocol (BGP) Pada Router Cisco 7606s
}

\author{
Darmawan $^{a}$, Teguh Imanto ${ }^{b}$ \\ ${ }^{a, b}$ Jurusan Teknik Elektro Fakultas Teknik Universitas Andalas, Kampus Unand Limau Manis, Padang, 25163, Indonesia
}

\begin{tabular}{|c|}
\hline INFORMASI ARTIKEL \\
\hline $\begin{array}{l}\text { Sejarah Artikel: } \\
\text { Diterima Redaksi: } 24 \text { Agustus } 2017 \\
\text { Revisi Akhir: } 17 \text { Desember } 2017 \\
\text { Diterbitkan Online: } 31 \text { Desember } 2017\end{array}$ \\
\hline KATA KUNCI \\
\hline failover, \\
\hline link balancing, \\
\hline bandwidth, \\
\hline Autonomous System \\
\hline KORESPONDENSI \\
\hline Telepon: +62 (0751) 12345678 \\
\hline E-mail: penulis_pertama@afiliasi.xx.xx \\
\hline
\end{tabular}

\section{A B S T R A C T}

Sistem link balancing dan failover merupakan salah satu cara yang dapat digunakan untuk membagi beban traffic dari client pada beberapa koneksi internet, dapat sebagai backup/failover ketika salah satu koneksi internet mengalami gangguan. Pada perancangan sistem ini digunakan 4 buah router, yaitu terdiri dari satu router cisco 7606s yang berfungsi sebagai main gateway yang mengatur sistem failover dan link balancing menuju ke 2 buah router mikrotik RB951G 2HND sebagai jalur kedua ISP dan router mikrotik CCR1036-12G-4S sebagai gateway dari FTP server. Tiap router tersebut memiliki Autonomus System Number yang berbeda yang saling berkomunikasi menggunakan routing Border Gateway Protocol (BGP). Dari hasil pengujian penggunaan link balancing dengan besar bandwidth $10 \mathrm{mb} / \mathrm{s}$, didapatkan throughput $794 \mathrm{~KB} / \mathrm{s}$, sedangkan yang tidak menggunakan link balancing dengan bandwidth sebesar $20 \mathrm{mb} / \mathrm{s}$, didapatkan nilai throughput hanya $136 \mathrm{~KB} / \mathrm{s}$. Penggunaan link balancing dapat memanfaatkan besar bandwidth yang ada dan meningkatkan throughput, dibandingkan tidak menggunkan link balancing. Pada pengujian delay, menggunakan link balancing hanya delay $1.24 \mathrm{~ms}$, sedangkan tidak menggunakan metode link balancing mencapai $8.19 \mathrm{~ms}$. Nilai latency didapatkan $12 \mathrm{~ms}$ untuk menggunakan link balancing sedangkan tidak menggunkan metode link balancing mencapai $1896 \mathrm{~ms}$.

\section{PENDAHULUAN}

Indonesia sebagai Negara berkembang mulai terus mengembangkan akses internet cepat di bawah pengawasan Kementerian Komunikasi dan Informatika yang lebih di kenal dengan Kominfo dari perusahaan swasta hingga persero saling berlomba-lomba merebutkan pangsa pasar akses internet. Dengan adanya jaringan internet cepat sangat membantu dalam berbagai bisnis juga mempercepat dalam berkomunikasi. ${ }^{[1]}$

Peningkatan pengguna jaringan internet sekarang ini tidak didukung dengan peningkatan mutu jaringan Internet yang sebanding. Oleh karena itu, banyak perusahaan penjual jasa Internet mencari solusi dengan menambah jumlah ISP untuk meningkatkan kapasitas bandwidth dan redundansi. ${ }^{[2]}$

Namun penerapan tersebut tidak semudah yang dibayangkan, terdapat permasalahan yang terjadi yaitu pengalokasian beban data yang tidak seimbang menuju ke 2 buah provider, serta perpindahan jalur ISP jika terjadi fault pada salah satu jalur tersebut. Maka dari itu, solusi yang dapat digunakan adalah implementasi link Balancing danfailover.

https://doi.org/10.25077/ TEKNOSI.v3i3.2017.326-333
Penelitian ini membahas penerapan metode Link Balancing dengan menggunakan router Cisco 7606s sebagai gateway untuk jaringan lokal dengan 2 provider yang berbeda dan kombinasi system failover. Koneksi banyak host ke jalur internet di manajemen pada sebuah router cisco 7606 s yang diterapkan sistem Link Balancing dan failover menggunakan Border Gateway Protocol (BGP) lalu terhubung ke 2 buah router sebagai gateway menuju ke 2 provider yang berbeda, sehingga sistem tersebut dapat memberikan solusi untuk kondisi permasalahan jaringan yang memiliki traffic yang sangat padat.

\section{TINJAUAN PUSTAKA}

\subsection{Load balancing}

Load balancing merupakan suatu teknik yang digunakan untuk memisahkan antara dua atau banyak network link. Dengan mempunyai banyak link maka optimalisasi utilisasi sumber daya, 
throughput, atau response time akan semakin baik karena mempunyai lebih dari satu link yang bisa saling mem-backup pada saat network down dan menjadi cepat pada saat network normal jika memerlukan $100 \%$ koneksi uptime dan yang menginginkan koneksi upstream yang berbeda dan dibuat saling mem-backup.

Load balancing atau penyeimbangan beban dalam jaringan sangat penting bila skala dalam jaringan komputer makin besar demikian juga traffic data yang ada dalam jaringan komputer makin lama makin tinggi. Layanan Load balancing dimungkinkan pengaksesan sumber daya dalam jaringan didistribusikan ke beberapa host lainnya agar tidak terpusat sehingga unjuk kerja jaringan komputer secara keseluruhan bisa stabil. ${ }^{[3]}$

Beberapa kelebihan implementasi load balancing secara umum, yaitu

1. Waktu respon akses yang lebih cepat dibandingkan dengan pembagian jalur secara statik, ini dikarenakan beban dibagi ke dalam beberapa jalur sehingga beban pada masingmasing jalur menjadi lebih ringan.

2. Pengaturan untuk mencegah terjadinya penumpukan beban pada salah satu jalur, atau bisa dikatakan pemerataan pembebanan pada masing - masing jalur.

3. Dapat memisahkan dan mengatur jaringan nasional dan internasional agar tidak terjadi saling tarik menarik bandwidth pada jaringan sistem tersebut.

4. Memperkecil kemungkinan terjadinya deadlock traffic yang sering kali terjadi pada perusahaan atau instansi.

5. Redundansi, bilamana salah satu server mati maka koneksi ke jaringan internet dapat tetap berjalan karena menggunakan lebih dari 2 ISP

\subsection{Failover}

Failover adalah teknik yang menerapkan beberapa jalur untuk mencapai suatu network tujuan. Namun dalam keadaan normal hanya ada satu link yang digunakan. Link yang lain berfungsi sebagai cadangan dan hanya akan digunakan bila link utama terputus.

\subsection{Border Gateway Protocol (BGP)}

Border Gateway Protocol atau yang sering disingkat BGP merupakan salah satu jenis routing protokol yang ada di dunia komunikasi data. Sebagai sebuah routing protokol, BGP memiliki kemampuan melakukan pengumpulan rute, pertukaran rute dan menentukan rute terbaik menuju ke sebuah lokasi dalam jaringan. Routing protokol juga pasti dilengkapi dengan algoritma yang pintar dalam mencari jalan terbaik. Namun yang membedakan BGP dengan routing protokol lain seperti misalnya OSPF dan IS-IS adalah BGP termasuk dalam kategori routing protokol jenis Exterior Gateway Protocol (EGP). Sesuai dengan namanya, EGP memiliki kemampuan pertukaran rute dari dan keluar jaringan lokal sebuah organisasi atau kelompok tertentu.

Organisasi atau kelompok tertentu diluar organisasi pribadi sering disebut dengan Autonomous System (AS). Maksudnya rute - rute yang dimiliki oleh sebuah AS dapat dimiliki oleh AS lainnya yang berbeda kepentingan dan otoritas. Begitu juga dengan AS tersebut dapat juga memiliki rute - rute yang dipunya organisasi lain dimana keuntungannya adalah organisasi anda bisa dikenal dengan organisasi - organisasi lain yang anda kirimi rute.

BGP dikenal sebagai routing protokol yang sangat kompleks dan rumit karena kemampuannya yang luar biasa ini, yaitu melayani pertukaran rute antar oraganisasi yang besar. Routing protokol ini memiliki tingkat skalabilitas yang tinggi karena karena beberapa organisasi dapat dilayaninya dalam melakukan pertukaran routing, sehingga luas sekali jangkauan BGP dalam melayani para pengguna jaringan ${ }^{[4]}$.

Routing protokol BGP baru dapat dikatakan bekerja pada sebuah router jika sudah terbentuk sesi komunikasi dengan router tetangganya yang juga menjalankan BGP. Sesi komunikasi ini adalah berupa komunikasi dengan protokol TCP dengan nomor port 179 . Setelah terjalin komunikasi ini, maka kedua buah router BGP dapat saling bertukar informasi rute. Setelah semuanya berjalan dengan baik, maka sebuah sesi BGP dapat bekerja dengan baik pada router. Untuk membentuk dan mempertahankan sebuah sesi BGP dengan router tetangganya, BGP mempunyai mekanismenya sendiri yang unik.

Pembentukan sesi BGP ini mengandalkan paket - paket pesan yang terdiri dari empat macam. Paket - paket tersebut adalah sebagai berikut:

1. Open Message

Sesuai dengan namanya, paket pesan jenis ini merupakan paket pembuka sebuah sesi BGP. Paket inilah yang pertama dikirimkan ke router tetangga untuk membangun sebuah sesi komunikasi. Paket inilah yang berisikan informasi mengenai $B G P$ version number, AS number, hold time dan router ID.

2. Keepalive Message

Paket keepalive message bertugas untuk menjaga hubungan yang telah terbentuk antar kedua router BGP. Paket jenis ini dikirimkan secara periodik oleh kedua buah router yang bertetangga. Paket ini berukuran 19 byte dan tidak berisikan data sama sekali.

3. Notification Message

Paket pesan ini adalah paket yang bertugas menginformasikan error yang terjadi terhadap sebuah sesi BGP. Paket ini berisikan field - field yang berisi jenis error apa yang telah terjadi, sehingga sangat memudahkan penggunaannya untuk melakukan troubleshoting.

4. Update Message

Paket update merupakan paket pesan utama yang akan membawa informasi rute - rute yang ada. Paket ini berisikan semua informasi rute BGP yang ada dalam jaringan tersebut. Ada tiga komponen utama dalam paket pesan ini, yaitu Network-Layer Reachability Information (NLRI), path atribut dan withdrawn routes.

\section{METODOLOGI}

\subsection{Load balancing}

Skema jaringan Link balancing dan failover 2 provider pada router Cisco 7606s dapat dilihat pada gambar 1

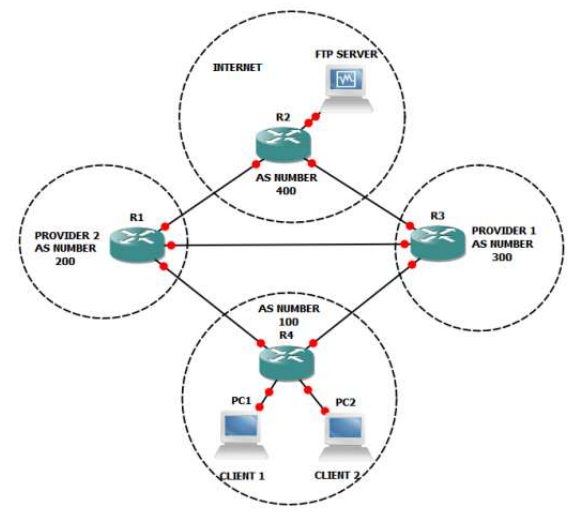

Gambar 1. Skema jaringan Link balancing 2 provider pada router cisco $7606 \mathrm{~s}$

Pada gambar 1 terdapat skema 4 buah router, dimana R4 merupakan router client yang terhubung dengan 2 buah jalur ISP yang berbeda yaitu R1 dan R3. Tiap router tersebut dibedakan berdasarkan AS Number yang berbeda. 


\subsection{Perangkat Sistem}

1. client

Prosesor: Intel(R) Core(TM) i5 CPU M $3802.53 \mathrm{GHz}$

RAM : $4096 \mathrm{MB}$

2. Router

Router 1 : Router Cisco 7606s

Router 2 : Router Mikrotik RB951G 2HND

Router 3 : Router Mikrotik RB951G 2HND

Router 4 : Router Mikrotik CCR1036-12G-4S

3. Server

Processor $\quad$ : Intel ${ }^{\circledR}$ Core TM $\mathrm{i} 3-2330 \mathrm{CPU} @ 2.20 \mathrm{GHz}$

(4 CPUs)

RAM

: $8192 \mathrm{MB}$

Storage

: HDD 1TB

Ethernet Card: Realtek PCIe GBE Family Controller

4. Operating System Komputer

Komputer Client: Windows 7 Home Premium 64bit

Komputer Server: Sistem operasi Linux Ubuntu Server 12.04 amd64.

\subsection{Traffic share dan count}

Pengujian Traffic Share Count ini, akan dilihat hasil pembagian traffic share, berdasarkan variasi perbandingan bandwidth antara ISP A dengan ISP B. Setiap variasi perbandingan bandwidth antar kedua ISP tersebut akan terlihat pembagian traffic count dari router cisco 7606s tersebut.

Proses pengujian Traffic Share Count sebagai berikut:

1. Atur tiap bandwidth tiap ISP A dan ISP B sesuai varias bandwidth yang telah ditetapkan, dengan perintah, \#configure terminal

\#Interface $\mathrm{f} 0 / 0$

\#bandwidth 100

\#exit

\# Interface $\mathrm{f} 0 / 1$

\#bandwidth 200

Lalu ketikan

show run

2. Untuk melihat hasil pengkonfigurasian router, dan hasilnya dapat dilihat pada gambar 2 .

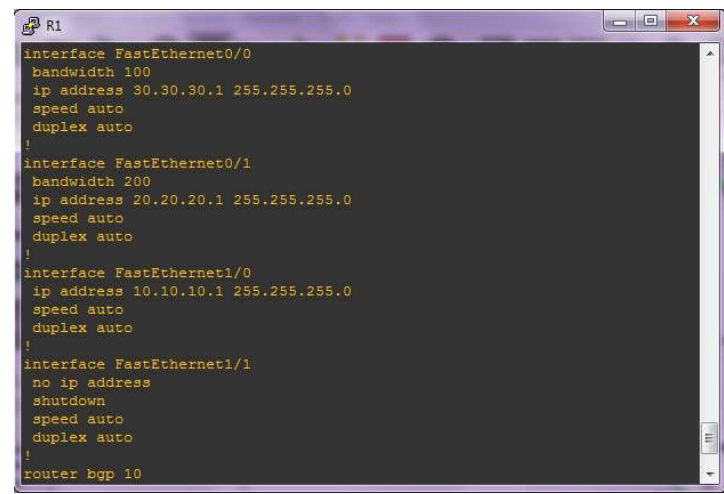

Gambar 2. Perbandingan bandwidth Jalur ISP A dan ISP B

Pada gambar 2 tersebut dapat dilihat hasil konfigurasi bandwidth antara ISP A dan ISP B, terlihat jalur f0/0 bandwidth tertulis 100 dan jalur f0/1 tertulis 200, bandwidth tersebut dalam satuan $\mathrm{Mb} / \mathrm{s}$.

3. Konfigurasi router tersebut agar dapat melakukan link balancing, dengan cara mengetikan pada router cisco perintah \#configure terminal

\#router bgp 10

\#no synchronization

\#bgp log-neighbor changes

\#bgp bestpath as-path multipath relax

\#bgp dmzlink-bw

\#neighbor 20.20.20.2 dmzlink-bw

\#neighbor 30.30 .30 .2 dmzlink-bw

\#maximum-path 2

\#no auto summary

\#exit

4. Lihat pembagian traffic share count dari masing-masing jalur ISP, dengan cara melihat jalur rute IP yang akan berkomunikasi ke IP loopback router server yaitu 4.4.4.4, dengan cara mengetikan:

show ip route 4.4 .4 .4

Maka akan terlihat hasil pembagian rute masing-masing ISP, seperti terlihat pada gambar 3 .

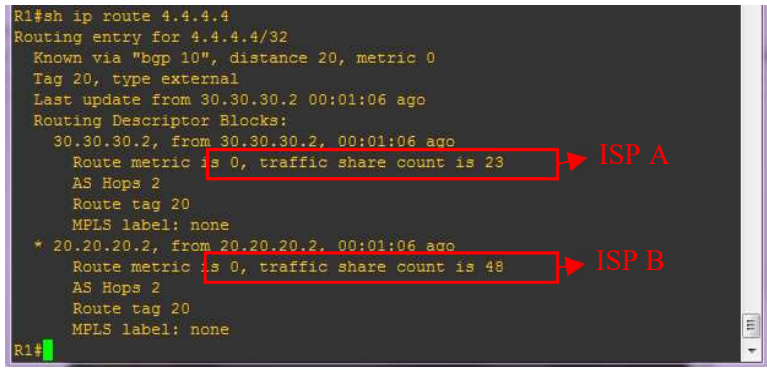

Gambar 3. Jumlah traffic share count berdasarkan perbandingan bandwidth

Pada gambar 3 diatas terlihat pembagian share traffic count pada masing-masing ISP. Terlihat pada gambar 3 diatas ditandai dengan garis merah, ISP A hanya mendapatkan 23 traffic share count, sedangkan ISP B mendapatkan 48 traffic share count. Hal tersebut terjadi karena bandwidth yang dikonfigurasi untuk ISP B lebih banyak dari pada ISP A yaitu 200, sehingga pembagian traffic banyak di lewatkan ke ISP B.

Langkah 1 sampai 3 diulangi untuk variasi bandwidth yang berbeda.

\subsection{Pengujian waktu response failover}

Pada pengujian waktu response failover, akan diuji berapa lama waktu response failover, atau waktu berpindahnya jalur data yang digunakan dari ISP utama ke ISP backup, dengan kondisi, hanya satu ISP yang berfungsi untuk menyalurkan data dan ISP lainnya sebagai backup apabila ISP utama terputus.

Adapun tahap proses pengujian waktu response failover adalah sebagai berikut:

1. Kirimkan paket ICMP dengan menggunakan perintah "PING" pada command prompt komputer clinet ke IP address komputer server untuk melihat terkoneksinya suatu jalur ke komputer server seperti yang terlihat pada gambar dibawah 4. 


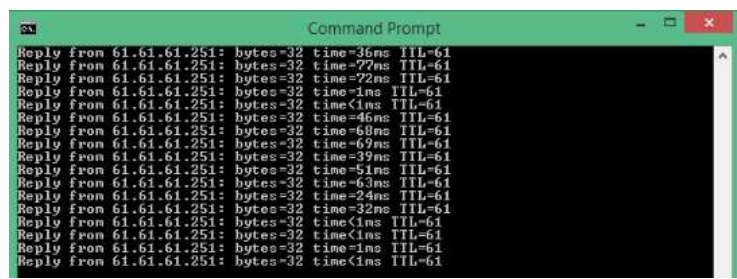

Gambar 4. Mengirimkan paket ICMP ke IP address komputer server

2. Untuk melihat jalur ISP yang dipakai untuk mengirimkan paket ICMP ke komputer server, ketikan perintah:

\#tracert (ip address server)

3. Pada saat bersamaan shutdown kan jaringan ISP B seolaholah jalur ISP B dalam keadaan fault atau gangguan yang dipakai untuk mengirimkan paket ICMP ke server dengan mengetikan perintah.

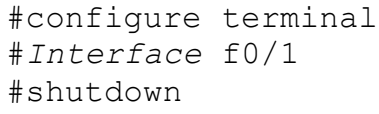

Maka terlihat seperti yang ada pada gambar 5 .

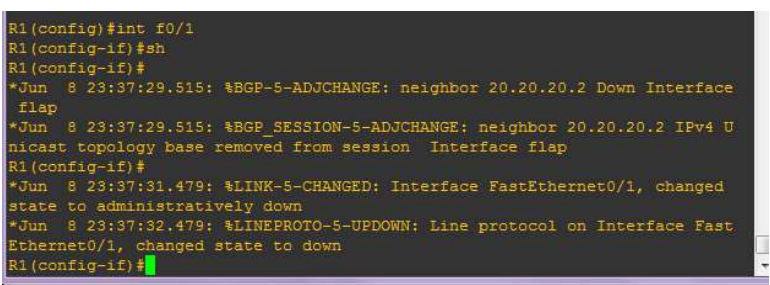

Gambar 5. Jalur ISP B dalam keadaan mati

Terlihat pada gambar 5 dibawah ini, jalur pengiriman paket ICMP dari jalur ISP B yaitu 20.20.20.2 berubah menggunakan jalur 30.30.30.2 atau jalur ISP A.

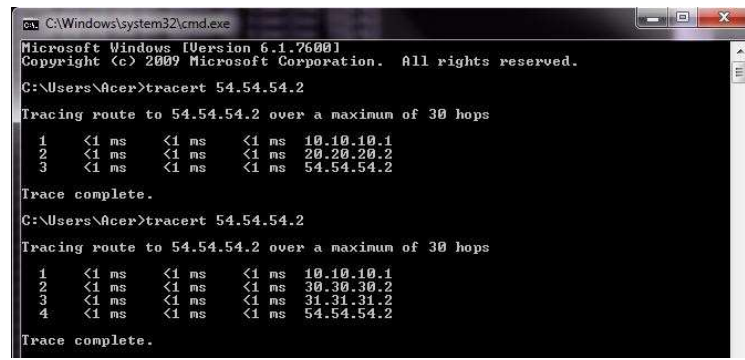

Gambar 6. Jalur ISP B berubah ke jalur ISP A

Pada saat saat bersamaan indiaktor perintah PING akan terlihat pada command prompt sepeti terlihat pada gambar 6 dibawah. Terlihat terjadi paket loss pada saat terjadi perpindahan jalur otomatis dari ISP B ke ISP A akibat terjadinya fault.

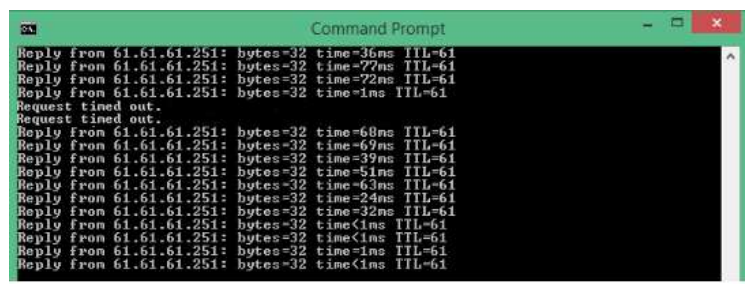

Gambar 7. Terjadinya paket loss saat ISP B berpindah ke ISP A

4. Lalu berapa lama waktu yang dibutuhkan sampai jalur paket ICMP dapat terkirim kembali saat setelah terjadi nya fault dicatat.
5. Langkah 1 sampai 4 diulangi kembali dengan mengganti jalur ISP utama yang berbeda.

\subsection{Kinerja Link balancing pada FTP Server}

Untuk pengujian Kinerja Link balancing pada FTP server, akan dilihat kinerja link balancing berupa, Througput, Delay, dan Latency pada saat keadaan traffic padat. Keadaan traffic padat disini menggunakan metoda traffic shape, yaitu dengan memotong bandwidth default kabel (100 MB/s) sebesar $16 \mathrm{~kb}$, sehingga jalur yang tersedia untuk mendowload file dari FTP server sangat kecil. Kinerja Link balancing ini akan dinilai baik atau tidak nya berdasarkan standar yang telah ditetapakan berdasarkan ITU-T atas tiga parameter diatas. Kinerja link balancing juga akan dinilai dengan membandingkan antara mengunggah file FTP server menggunakan link balancing dengan tanpa menggunakan link balancing, tanpa menggunakan link balancing disini artinya hanya satu ISP yang berfungsi sebagai jalur lewatnya paket, setelah itu akan dinilai hasil perbedaannya untuk melihat kinerja hasil keduanya.

Tahap proses pengujian Kinerja Link balancing adalah sebagai berikut:

1. Untuk pengujian File FTP server tanpa mnggunakan link balancing, pertama cek terlebih dahulu, antara client dan server telah terhubung dengan mentracert terlebih dahulu dari client ke FTP server seperti pada gambar 4.10 dibawah ini.

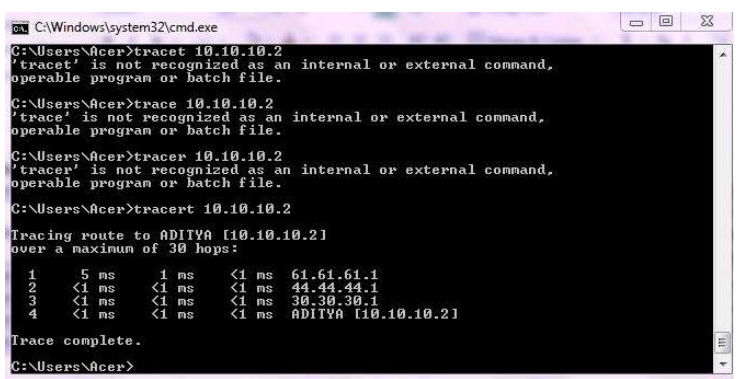

Gambar 8. Komputer client dengan komputer server telah tersambung

Terlihat pada gambar 8 diatas antara client dan server telah tersambung dengan baik hanya melalui jalur ISP A.

2. Jika telah terkoneksi, maka selanjtunya dengan mengakses file ftp server, dengan cara mengetikan pada web browser client :

\section{\#ftp: / /ipaddressserver}

maka akan terlihat pada gambar 9 dibawah file FTP server akan tampil pada tampilan web browser dengan variasi ukuran file yang berbeda.

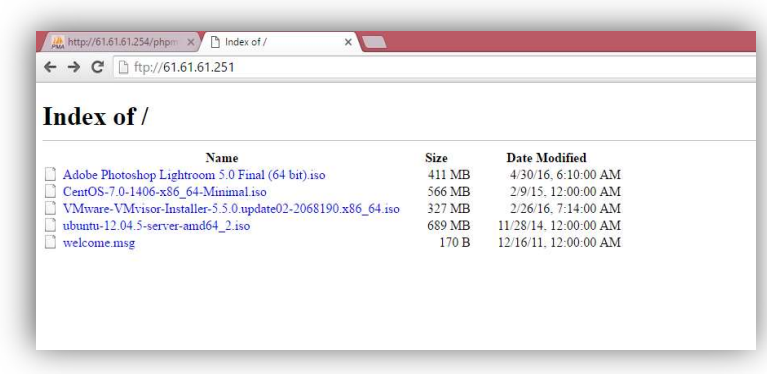

Gambar 9. Tampilan File FTP server pada web browser komputer client 
3. Memotong bandwidth sebesar $16 \mathrm{~Kb}$ pada jalur ISP yang aktif digunakan untuk mendownload file FTP server dengan metode traffic shape. dengan perintah

\#configure terminal

\#Interface f0/1

\#traffic-shape rate 16000

4. Untuk mendapatkan data latency, yaitu dengan cara mengirimkan paket ICMP ke server dari komputer client ke server pada saat mendownload file.

5. Sebelum mendownload file, capture terlebih dahulu dengan menggunakan wireshark untuk mendapatkan data throughput dan delay

6. Langkah 1 sampai 5 diulangi dengan variasi kapasitas file yang berbeda.

Untuk percobaan dengan menggunakan link balancing, langkah-langkah pengujian sama dengan yang diatas, tetapi dengan menggunakan 2 ISP sekaligus dengan menerapkan link balancing.

\section{HASIL DAN PEMBAHASAN}

\subsection{Data Traffic Share Count Berdasarkan Perbandingan Bandwidth}

Dari hasil pengujian traffic count berdasarkan perbandingan bandwidth, didapatkan hasil pada tabel 1 dibawah ini.

Tabel 1 Nilai traffic share count berdasarkan perbandingan bandwidth

\begin{tabular}{ccccc}
\hline No & \multicolumn{2}{c}{ Bandwidth $(\mathrm{Mb} / \mathrm{s})$} & \multicolumn{2}{c}{ Traffic share count } \\
& ISP A & ISP B & ISP A & ISP B \\
\hline 1 & 100 & 100 & 1 & 1 \\
2 & 100 & 200 & 23 & 48 \\
3 & 100 & 225 & 1 & 2 \\
4 & 100 & 250 & 77 & 240 \\
5 & 200 & 200 & 1 & 1 \\
6 & 200 & 400 & 2 & 5 \\
7 & 200 & 450 & 47 & 120 \\
8 & 200 & 500 & 77 & 240 \\
9 & 300 & 300 & 1 & 1 \\
10 & 300 & 600 & 2 & 5 \\
11 & 300 & 675 & 43 & 120 \\
12 & 300 & 750 & 77 & 240 \\
13 & 400 & 400 & 1 & 1 \\
14 & 400 & 800 & 1 & 2 \\
15 & 400 & 900 & 109 & 240 \\
16 & 400 & 1000 & 2 & 5 \\
\hline
\end{tabular}

Dari tabel 1 diatas maka dapat direpresentasikan perbandingan nilai bandwidth dengan traffic count pada gambar 10 dibawah ini.

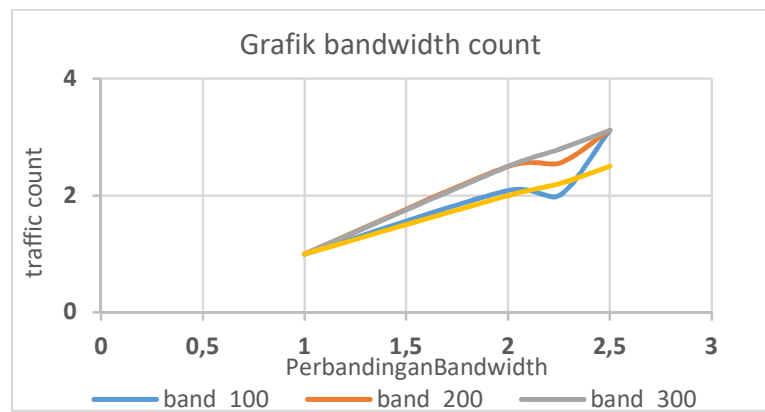

Gambar 10.Perbandingan Traffic Share Count ISP A dengan ISP $\mathrm{B}$ dengan variasi nilai bandwidth yang berbeda

Dari hasil yang diperlihatkan pada gambar 10 diatas, pembagian bandwidth yang tidak merata terdapat pada besar bandwidh 200 $\mathrm{Mb} / \mathrm{s}$ dan $300 \mathrm{Mb} / \mathrm{s}$. Jika nilai traffic count melebihi dari nilai perbandingan bandwidth, maka ISP B akan terbebani, dan jika nilai traffic count kurang dari nilai perbandingan bandwidth maka ISP A yang akan terbebani. Terlihat pada grafik diatas pada besar bandwidth $200 \mathrm{Mb} / \mathrm{s}$ dan $300 \mathrm{Mb} / \mathrm{s}$, pembagian traffic count rata-rata selalu melebihi dari nilai perbandingan bandwidth, sehingga ISP B yang selalu terbebani.

Berbeda halnya pada besar bandwidth $400 \mathrm{Mb} / \mathrm{s}$, terlihat traffc count hampir sama dengan nilai perbandingan bandwidthnya, hanya pada perbandingan 2.25 terdapat sedikit perbedaan yaitu 0.05 , sehingga pada perbandingan bandwidth $400 \mathrm{Mb} / \mathrm{s}$ memiliki traffic share yang ideal atau pembagian yang adil dalam membagi beban traffic ke ISP A dan ISP B.

Dari grafik diatas terlihat, perbandingan nilai bandwidth yang sama tetapi besar bandwidth berberda, didapatkan pembagian traffic count nya berbeda. Rata-rata di nilai bandwidth yang lebih besar, pembagian traffic count nya lebih tidak linier.

Perbandingan bandwidth dengan traffic count yang ditampilkan pada tabel 1, maka akan didapatkanlah perbandingan nilai bandwidth rata-rata dengan dengan traffic count rata-rata, dari tiap-tiap besar bandwidth dan traffic count yang berbeda, yang disajikan dalam bentuk grafik pada gambar 11 dibawah ini.

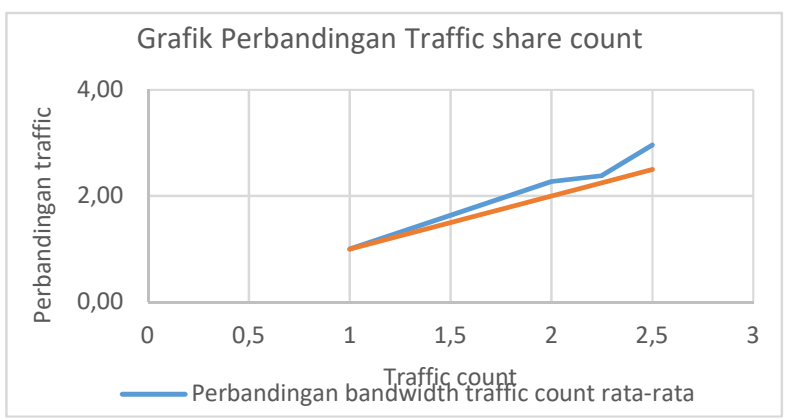

Gambar 11. Perbandingan Traffic Count rata-rata antara ISP A dengan ISP B

Pada gambar 11 diatas terlihat bahwa perbandingan bandwidth terhadap pembagian traffic count tidak linier atau tidak sama rata. Terlihat rata-rata semakin tinggi nilai perbandingan bandwidth, maka semakin besar pula nilai traffic count menjauhi dari titik ideal. Sehingga ISP B akan selalu terbebani dalam melalui traffic. Perbandingan yang ideal hanya didapatkan pada perbandingan bandwidth 1:1 yang didapatkan nilai traffic count yang sama dengan perbandingan bandwidth. 


\subsection{Data Waktu Response failover}

Dari hasil pengujian waktu response failover pada cisco 7606s, didapatkan hasil pada tabel 10 dibawah ini.

Tabel 2. Waktu response failover

\begin{tabular}{clcc}
\hline No & $\begin{array}{c}\text { ISP yang } \\
\text { digunakan }\end{array}$ & kondisi & $\begin{array}{c}\text { waktu } \\
\text { response } \\
\text { failover }\end{array}$ \\
\hline 1 & A (default) & ON => OFF & 4 detik \\
\cline { 2 - 3 } & B (backup) & \\
\cline { 1 - 2 } & B (default) & ON => OFF detik & \\
\cline { 2 - 3 } & A (backup) & & 2 detik \\
\cline { 1 - 2 } & Rata - Rata &
\end{tabular}

Pada tabel 2 diatas terlihat waktu response failover yang diambil implementasi secara langsung menggunakan router Cisco 7606s. Ketika ISP A sebagai ISP utama dan ISP B sebagai backup, ketika ISP A tersebut dimatikan atau diset dalam keadaan down, maka waktu perpindahan jalur data ke ISP B membutuhkan waktu hanya 4 detik. Sedangakan ketika ISP B berganti sebagai ISP utama dan ISP A sebagai backup, lalu ISP A tersebut dimatikan atau diset dalam keadaan down, maka perpindahan jalur data ke ISP A tidak membutuhkan waktu, dapat diartikan 0 detik, atau tidak terjadinya paket loss. Sehingga jika dirata-ratakan waktu response failover untuk implentasi secara langsung hanya membutuhkan waktu 2 detik.

Jika berlandaskan pada standarisasi komunikasi ITU-T pada tabel 3.

Tabel 3. Standarisasi ITU-T Paket loss

\begin{tabular}{lll}
\hline Kategori Degredasi & Packet Loss & Indeks \\
\hline Sangat Bagus & $0 \%$ & 4 \\
\hline Bagus & $3 \%$ & 3 \\
\hline Sedang & $15 \%$ & 2 \\
\hline Jelek & $25 \%$ & 1 \\
\hline
\end{tabular}

(Sumber: TIPHON ${ }^{[14]}$

Perpindahan rata-rata selama 2 detik tersebut sangat bagus. Karena waktu 2 detik jika mengirimkan PING atau mengirimkan paket ICMP, hanya terjadi 1 paket loss atau paket yang dibuang.

Kita anggap jumlah paket 100 buah yang akan dikirimkan sehingga:

$$
\% \text { Paketloss }=\frac{100-99}{100} \times 100 \%=1 \%
$$

Dari hasil yang didapat sistem failover menggunakan router cisco 7606s sangat direcomendasikan karena masuk dalam kategori sangat bagus.

\subsection{Kinerja Link balancing pada FTP server}

Pada pengujian besar throughput diatas, dengan varisasi besar bandwidth yang berbeda, yaitu besar bandwidth yang tidak menggunakan link balancing lebih besar dua kali lipat dari yang menggunakan link balancing. Hal tersebut untuk membuktikan dengan menggunkan link balancing menggunkan 2 jalur dengan bandwidth masing $10 \mathrm{mb} / \mathrm{s}$ dikedua jalur, apakah memiliki throughput yang sama dengan yang tidak menggunakan link balancing yang menggunakan 1 jalur tetapi memiliki besar bandwidth yang sama besar dengan pemakaian 2 jalur yaitu 20 $\mathrm{mb} / \mathrm{s}$.

Dari pengujian link balancing dengan variasi bandwidth didapatkan hasil pada tabel 4 dibawah ini :

Tabel 4. Perandingan throughput pengujian kinerja link balancing pada FTP Server variasi bandwidth

\begin{tabular}{llll}
\hline No & $\begin{array}{l}\text { Besar bandwidth } \\
\text { (link balancing } \\
\text { dan non link } \\
\text { balancing) }(\mathrm{KB} / \mathrm{s})\end{array}$ & $\begin{array}{l}\text { Man Lenguna } \\
\text { balancing } \\
(\mathrm{KB} / \mathrm{s})\end{array}$ & $\begin{array}{l}\text { Tanpa } \\
\text { Link balancing } \\
(\mathrm{KB} / \mathrm{s})\end{array}$ \\
\hline 1 & 1250 dan 2500 & 794 & 136 \\
2 & 1500 dan 3000 & 726 & 183 \\
3 & 1750 dan 3500 & 1000 & 200 \\
\hline
\end{tabular}

Tabel 4 diatas dapat direpresntasikan dalam bentuk grafik pada gambar 12

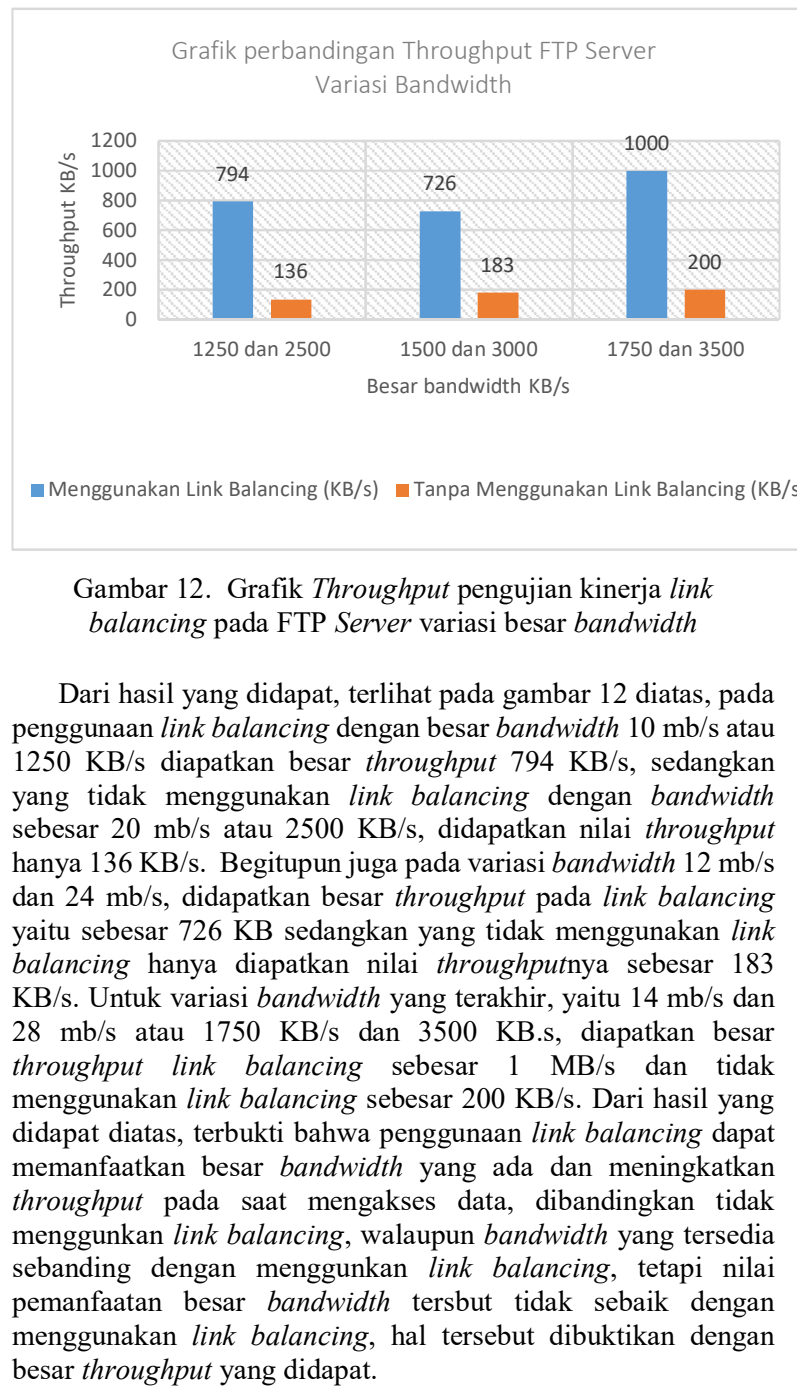




\subsection{Kinerja Link balancing pada FTP server Variasi Ukuran File}

\subsubsection{Delay}

Dari hasil pengujian throughput didapatkan hasil pada tabel 5 dibawah ini.

Tabel 5. Perandingan Delay pengujian kinerja link balancing pada FTP Server variasi ukuran file

\begin{tabular}{llll}
\hline No & $\begin{array}{l}\text { Ukuran } \\
\text { File } \\
(\mathrm{MB})\end{array}$ & $\begin{array}{l}\text { Menggunakan } \\
\text { Link balancing } \\
(\mathrm{ms})\end{array}$ & $\begin{array}{l}\text { Tanpa } \\
\text { Menggunakan Link } \\
\text { balancing (ms) }\end{array}$ \\
\hline 1 & $300 \mathrm{MB}$ & 1.71 & 9.17 \\
\hline 2 & $400 \mathrm{MB}$ & 2.44 & 8.19 \\
\hline 3 & $500 \mathrm{MB}$ & 1.24 & 8.19 \\
\hline
\end{tabular}

Tabel 5 diatas dapat direpresntasikan dalam bentuk grafik pada gambar 13 .

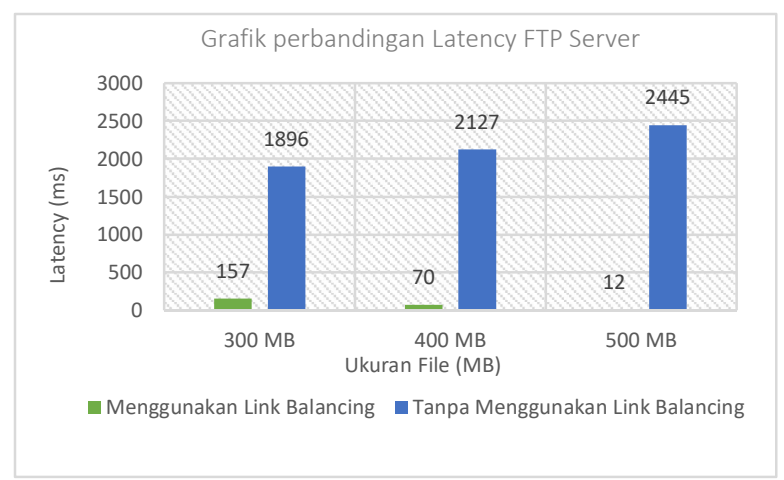

Gambar 13. Grafik Delay pengujian kinerja link balancing pada FTP Server variasi ukuran file

Pada gambar 13 diatas juga terdapat perbedaan yang sangat signifikan antara penggunaan link balancing dan tidak meenggunakan link balancing, besar delay pada saat pengiriman file pada tidak menggunakan link balancing sangat besar dari pada menggunaka link balancing. Selisih perbedaannya mencapai rata-rata sebesar $6.72 \mathrm{~ms}$. Padanya traffic dalam satu jaringan sangat mempengaruhi delay dalam pengiriman suatu file, padatnya traffic pada suatu jaringan mengharuskan suatu router memberikan kebijakan untuk melakukan antrian suatu paket, semakin besar traffic, maka semakin banyak pula paket yang akan mengantri. Seperti itulah yang terjadi pada pengujian tidak menggunakan link balancing, penggunaan satu jalur pada saat traffic padat, mengakibatkan antrian pada paket tersebut, sehingga delay yang terjadi pada saat pengiriman sangatlah tinggi. Berbeda jika menggunakan metoda link balancing, penggunaan 2 buah jalur ISP, meminimalisir antrian yang terjadi pada suatu router, pembagian beban pun menghindarkan akan terjadinya traffic padat, sehingga waktu yang dibutuhkan dalam pengiriman data pun akan jauh lebih singkat.

\subsubsection{Latency}

Dari hasil pengujian latency didapatkan hasil pada tabel 6 dibawah ini.
Tabel 6 Perandingan latency pengujian kinerja link balancing pada FTP Server variasi ukuran file

\begin{tabular}{llll}
\hline No & $\begin{array}{l}\text { Ukuran File } \\
(\mathrm{MB})\end{array}$ & $\begin{array}{l}\text { Menggunakan } \\
\text { Link balancing } \\
(\mathrm{ms})\end{array}$ & $\begin{array}{l}\text { Tanpa } \\
\text { Menggunakan } \\
\text { Link balancing } \\
(\mathrm{ms})\end{array}$ \\
\hline 1 & $300 \mathrm{MB}$ & 157 & 1896 \\
\hline 2 & $400 \mathrm{MB}$ & 70 & 2127 \\
\hline 3 & $500 \mathrm{MB}$ & 12 & 2445 \\
\hline
\end{tabular}

Tabel 6 diatas dapat direpresentasikan dalam bentuk grafik pada gambar 14 dibawah ini.

Pada pengujian Latency, seperti yang terlihat pada gambar 14, pengiriman transfer file pada metoda tanpa menggunakan link balancing memiliki nilai latency yang tinggi. Besarnya latency dapat mempengaruhi kualitas dari suatu jaringan. Latency Adalah waktu yang dibutuhkan data untuk menempuh jarak dari asal ke tujuan lalu kembali ke sumber.

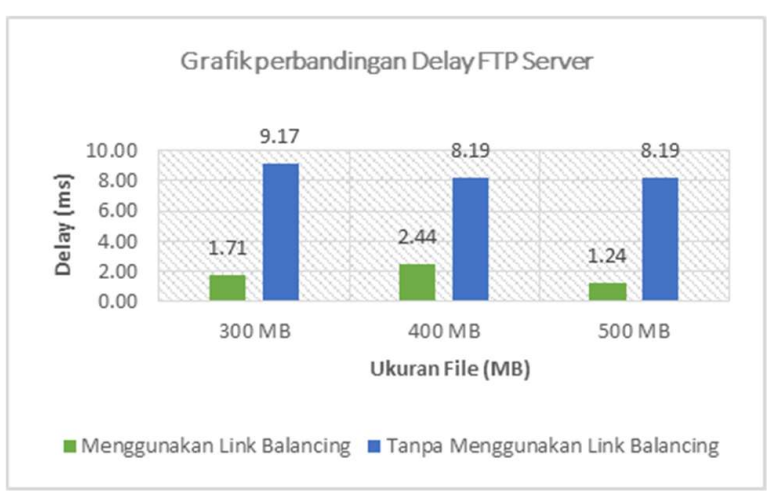

Gambar 14 Grafik Latency pengujian kinerja link balancing pada FTP Server variasi ukuran file

Berdasarkan standariasai ITU-T besarnya latency dapat diklasifikasikan sebagai berikut.

Tabel 7. Standarisasi ITU-T Latency

\begin{tabular}{lll}
\hline Kategori Latensi & Besar Delay & Indeks \\
\hline Sangat Bagus & $<150 \mathrm{~ms}$ & 4 \\
\hline Bagus & $150 \mathrm{~s} / \mathrm{d} 300 \mathrm{~ms}$ & 3 \\
\hline Sedang & $300 \mathrm{~s} / \mathrm{d} 450 \mathrm{~ms}$ & 2 \\
\hline Jelek & $>450 \mathrm{~ms}$ & 1
\end{tabular}

(Sumber: TIPHON) ${ }^{[5]}$

Jika kita melihat pada standarisasi pada tabel 7 di atas maka metoda penggunaan link balancing pada saat traffic padat sangat dianjurkan, dikarenakan pada saat traffic padat besar nilai latency masih dikategorikan sangat bagus yaitu $<150 \mathrm{~ms}$. berbeda halnya ketika tanpa menggunakan link balancing, pada saat traffic padat, ketika mengirimkan file FTP, nilai latency yang dihasilkan sangat besar yaitu $2156 \mathrm{~ms}$, dan masuk dalam kategori jelek $>450 \mathrm{~ms}$. 


\section{KESIMPULAN}

Berdasarkan hasil pengujian dan analisa, dapat disimpulkan bahwa, Perbandingan bandwidth 1:1 adalah perbandingan bandwidth yang sangat ideal, terlihat pada pengujian traffic count dan traffic share, perbandingannya selalu sama.

Penggunaan link balancing dapat memanfaatkan besar bandwidth yang ada dan meningkatkan throughput pada saat mengakses data, dibandingkan tidak menggunkan link balancing, walaupun bandwidth yang tersedia sebanding dengan menggunkan link balancing, tetapi nilai pemanfaatan besar bandwidth tersbut tidak sebaik dengan menggunakan link balancing, hal tersebut dibuktikan dengan besar throughput yang didapat. Pada penggunaan link balancing dengan besar bandwidth $10 \mathrm{mb} / \mathrm{s}$ atau $1250 \mathrm{~KB} / \mathrm{s}$ diapatkan besar throughput $794 \mathrm{~KB} / \mathrm{s}$, sedangkan yang tidak menggunakan link balancing dengan bandwidth sebesar $20 \mathrm{mb} / \mathrm{s}$ atau $2500 \mathrm{~KB} / \mathrm{s}$, didapatkan nilai throughput hanya $136 \mathrm{~KB} / \mathrm{s}$.

Perbedaan penggunaan metode link balancing dengan tidak menggunakan link balancing pada saat keadaan traffic padat, sangat jauh berbeda. Hal tersebut terlihat pada perbedaan throughput, delay, dan latency. Throughput pada saat menggunakan metode link balancing pada traffic padat dapat mencapai $8.21 \mathrm{MB} / \mathrm{s}$, sedangkan tidak menggunakan metode link balancing hanya mencapai $1.25 \mathrm{MB} / \mathrm{s} /$. Begitu juga pada delay, menggunakan link balancing pada saat pengiriman paket hanya terjadi delay $1.24 \mathrm{~ms}$ dibandingkan dengan tidak menggunakan metode link balancing yaitu mencapai 8.19 ms. Sedangkan nilai latency juga sangat jauh berbeda, yaitu $12 \mathrm{~ms}$ untuk menggunakan link balancing dan sedangkan tidak menggunakan metode link balancing dapat mencapai 1896. Terbukti Bahwa penggunaan link balancing sangat baik. Hal tersebut dibuktikan pada 3 parameter tersebut yang dikategorikan sangat bagus dalam standarisasi komunikasi ITU-T. Sedangkan untuk tidak menggunakan link balancing dikategorikan jelek.

Sistem Respon failover pada cisco 7606s sangat baik, hal tersebut dibuktikan bahwa waktu respon failover atau perpindahan ISP pada saat tejadinya fault, adalah rata-rata 2 detik, waktu 2 detik jika di translasikan pada pengiriman paket ICMP, hanya terjadi 1 paket loss.

\section{DAFTAR PUSTAKA}

[1] http://www.kompasiana.com/www.operaja.com/info-daftar-23besar-isp wilayah-dki-jakarta 54f5f4fca33311b07d8b46al. [29 Maret 2016]

[2] Maulana, Aldana Eka .dkk. 2013. "Jurnal teknik Komputer Vol.21 No.21". Binus : Jakarta Barat

[3] http://repository.usu.ac.id/bitstream/123456789/33714/4/Chapter \%20II.pdf. [ 25 Maret 2016]

[4] Rafiudin Rahmat. 2004. Multihoming Menggunakan BGP. Jakarta: Yogyakarta: Andi

[5] Etsi. Telecommunication and Internet Protocol Harmonization Over Network (TIPHON) General aspect of Quality of Service (QoS). www.etsi.org. [26 Maret 2016]

\section{BIODATA PENULIS}

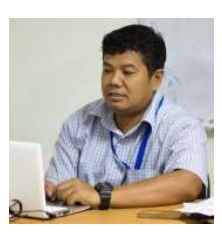

Darmawan merupakan staf pengajar di Jurusan Teknik Elektro Fakultas Teknik Universitas Andalas. Menyelesaikan S1 di Jurusan Teknik Elektro Fakultas Teknik Universitas Andalas dan Master di bidang Mechatronics Engineering pada International Islamic University of Malaysia. 